\title{
A Percepção na Transformação da Paisagem: Os Agricultores no Desflorestamento de Engenheiro Beltrão - Paraná, 1948-1970
}

\author{
Ely Bergo de Carvalho* \\ Eunice Sueli Nodari* ${ }^{* *}$
}

\begin{abstract}
Resumo:
A expansão da fronteira agrícola é a principal causa do desflorestamento no Brasil e estudar a percepção dos agricultores é fundamental para entender tal processo. Esta pesquisa de história ambiental se limita ao município de Engenheiro Beltrão, Paraná, no período de 1948, início da colonização dirigida, até 1970. Foi utilizada a metodologia de história oral, sendo elaboradas 37 entrevistas. O objetivo principal é entender como agricultores se apropriaram e representaram a floresta.
\end{abstract}

Palavras-chave: desflorestamento, representação, apropriação, agricultores.

\section{O “SERTÃO”}

Qualquer um que tenha conhecido o município de Engenheiro Beltrão, no Norte do Estado do Paraná, nos últimos vinte anos, viu uma região agrícola, altamente tecnificada, que produz soja, milho, trigo, cana-de-açúcar, a qual dificilmente chamaria de “sertão”. O “sertão” parecia ser mais adiante, como na região amazônica, e não ali. Todavia, na década de 1950, Engenheiro Beltrão aparecia na imprensa regional como "a boca do sertão”, e assim é lembrado por seus agricultores.

Na segunda metade do século XX a “colonização” e a “modernização” alteram tal representação. "Foi no processo de transformação da paisagem de grande parte do território paulista, do norte do Estado do Paraná e outras regiões, que se eliminou a ‘memória', a representação daqueles espaços como ‘sertões’”' (Arruda, 2000, p. 14).

Conhecemos apenas a percepção das elites sobre tal processo, das pessoas em geral pouco se sabe:

\footnotetext{
O impacto causado na forma de vida e de percepção dos homens que participaram da "conquista do oeste" brasileiro, da chamada "marcha do café rumo ao oeste”, continua sendo desconhecido pela historiografia. ... não sabemos como este novo mundo criado, com as suas novas formas de ocupação, as cidades recém-surgidas, as ferrovias, a eletricidade, os novos ritmos de trabalho e a utilização da natureza, foi lido e incorporado pelos que participaram deste processo. (Arruda, 2000, p. 20)
} 
Os agricultores beltrandenses, estudados nesta pesquisa, ${ }^{1}$ são justamente alguns dos sujeitos que participaram do processo de transformação do "sertão" em “civilização”. Nosso objetivo é entender as formas como agricultores se apropriaram e representaram a floresta, para compreender melhor o processo de transformação do “sertão” em civilização.

\section{ENGENHEIRO BELTRÃO: (RE)OCUPAÇÃO E PADRÃO FUNDIÁRIO}

O município de Engenheiro Beltrão está localizado no terceiro planalto paranaense, às margens do rio Ivaí, entre este e o rio Piquiri. Mas, de fato, em meados do século XIX, quando a então quinta comarca da província de São Paulo foi transformada na Província do Paraná, o terceiro planalto paranaense era coberto predominantemente por uma exuberante floresta. Então, a “população oficial” da província estava concentrada no litoral e no primeiro e segundo planaltos, sendo que, a partir desta época, tal “sertão” sofre um processo de (re)ocupação, com a incorporação ao mercado capitalista. Deve-se esclarecer que se utiliza o conceito de (re)ocupação do “sertão” paranaense, uma vez que ele já estava ocupado por indígenas e caboclos (Tomazi, 1997).

A (re)ocupação da atual área de Engenheiro Beltrão se insere, dentro do processo de (re)ocupação do “sertão” paranaense, principalmente a partir do boom da lavoura cafeeira, após 1945, efetuada por uma empresa privada, a Sociedade Técnica Colonizadora Engenheiro Beltrão Ltda., fundada em 1947 por uma família ligada ao governo do Estado, a família Beltrão, para colonizar terras, como a Gleba Rio Mourão, com 40.762,16 hectares, da qual se formará Engenheiro Beltrão.

Apesar de a Sociedade Técnica Colonizadora Engenheiro Beltrão conter em seu contrato social um amplo objetivo para a sociedade, a saber: adquirir terras "dos próprios sócios ou terceiros, para nelas e em áreas de terceiros, mediante contrato, serem exercidas atividades técnicas de engenharia civil, trabalhos de colonização, urbanismo e saneamento, exploração agrícolas e industriais” (Escritura... 1947). Os entrevistados foram unânimes em afirmar que a Sociedade Técnica Colonizadora Engenheiro Beltrão não se envolvia diretamente com o "negócio de madeira”, sua ação se restringia a vender as terras (a especular) e a providenciar, ou não, a devida infraestrutura básica. 
Quanto a forma de (re)ocupação utilizada na região é chamada de

“colonização dirigida”, ou seja, “aquela efetuada por particulares, por empresas ou pelo Poder Público, cujo planejamento antecede a vinda de colonos. O objetivo é a venda de terras e a promoção do povoamento. Os lotes são divididos e demarcados, são assegurados meios de comunicação e transporte”. (Cancian, 1977, p. 135)

As técnicas de “colonização”, utilizadas pela Sociedade Técnica Colonizadora Engenheiro Beltrão Ltda., foram as mesmas utilizadas por outras empresas e pelo Estado, com a construção de estradas nos espigões, e a divisão dos lotes de forma que tivessem acesso a estrada e água, assegurando a produção.

A Sociedade Técnica Colonizadora Engenheiro Beltrão Ltda., ao planejar a (re)ocupação, já o fez com base nas pequenas e médias propriedades (Beltrão, 1947). Todavia a estrutura fundiária produzida não foi nada democrática.

O censo agropecuário de 1970 nos fornece dados para melhor entender a estrutura fundiária de Engenheiro Beltrão. Apenas 314 estabelecimentos contrataram mão-de-obra. Assim, podemos concluir que o restante dos estabelecimentos, 2.217, trabalhava pelo regime familiar. Ocorre que, em geral, quem contratava trabalhadores assalariados eram as fazendas. Em 1970, foram 1.278 pessoas, entre trabalhadores temporários e permanentes. O médio proprietário, ou melhor, aquele que tinha uma área que não conseguia ser mantida apenas pela sua família, entregava a área excedente, normalmente pelo regime de parceria, sendo de parceiros a maioria dos estabelecimentos, 1.415 em um total de 2.531.

Desta forma, em 1970, os arrendatários e parceiros — "não proprietários” — representavam 59,6\% dos estabelecimentos rurais. Mesmo considerando que parte desses arrendatários pudesse ser proprietária de um outro estabelecimento, deve-se atentar que, da população rural total de 25.239, 5,85\% eram empregados em trabalhos temporários e permanentes. Ou seja, a maioria da população, que vivia da terra, estava excluída da propriedade da terra. ${ }^{2}$ Tal modelo de (re)ocupação de terra é importante para entender as formas de apropriação da floresta.

\section{E OS AGRICULTORES DERRUBARAM A MATA}

A cobertura vegetal dominante na área do atual município de Engenheiro Beltrão, antes do desflorestamento, era uma densa e grande floresta, com árvores que alcançavam 35 metros. Classificada por Reinhard Maack como floresta estacional 
semidecidual (ou floresta pluvial tropical do terceiro planalto) (Engenheiro Beltrão, 1996), uma floresta latifoliada, a qual ao menos em termos legais pertence ao ecossistema da Mata Atlântica (Brannstrom, 2002, p. 70-71). O processo de desflorestamento foi tão radical que o Censo Agropecuário apresenta que, em 1975, apenas 59, em um universo de 1.289 estabelecimentos, declararam ter áreas com “matas naturais”, num total de 1.571 hectares (Tabela 1).

\begin{tabular}{|c|c|c|c|c|c|c|c|c|c|c|}
\hline \multicolumn{11}{|c|}{ TABELA 1 - ENGENHEIRO BELTRÃO - PR.: UTILIZAÇÃO DAS TERRAS } \\
\hline & \multicolumn{2}{|c|}{1960} & \multicolumn{2}{|c|}{1970} & \multicolumn{2}{|c|}{1975} & \multicolumn{2}{|c|}{1985} & \multicolumn{2}{|c|}{$1995 / 96$} \\
\hline & Área** & Info* & Área** & Info* & Área** & Info* & Área** & Info* & Área** & Info* \\
\hline Lavoura perma & 12.306 & 583 & 11.975 & 1.337 & 7.531 & 541 & 3.209 & 372 & 1.210 & 180 \\
\hline Lavoura temporária & 5.092 & 643 & 16.289 & 1.942 & 22.750 & 1.024 & 27.591 & 1.031 & 31.439 & 711 \\
\hline Pastagens naturais & 51 & 5 & 28 & 7 & 2.735 & 419 & 770 & 61 & 535 & 52 \\
\hline ens planta & 2.455 & 422 & 8.667 & 1.069 & 3.774 & 264 & 6.788 & 452 & 7.263 & 436 \\
\hline Mat & 4.730 & 213 & 2.327 & 164 & 1.571 & 59 & 2.113 & 107 & 1.858 & 251 \\
\hline Matas plantadas & 53 & 1 & 88 & 27 & 122 & 26 & 129 & 55 & 988 & 166 \\
\hline Terras incultas & 39 & 4 & 938 & 144 & 1.555 & 132 & 498 & 70 & 1.776 & 53 \\
\hline Total & 24.726 & & 40.312 & & 40.038 & & 41.098 & & 45.069 & \\
\hline Fonte: IBGE. Censo & opecuário & o de 1 & $60 / 1970$ & $/ 1975 / 1$ & 1985 e 19 & $95 / 96$. & & *Inforn & nantes ** & *(ha) \\
\hline
\end{tabular}

As aspirações dos agricultores entrevistados, quando chegaram ao município, talvez possam ser resumidas com as idéias de "melhorar de vida” e "aumentar as terras”, isto é, “prosperar”. Isso implicou derrubar a floresta e cultivar a terra.

A grande incidência de pequenos agricultores na região contribuiu para o desflorestamento. Como já salientou Warren Dean, ao constatar que na primeira metade do século XX temos, em várias regiões do Brasil, um processo de parcelamento em pequenas propriedades da terra, ele afirma:

A passagem para a pequena propriedade alterava, pois, a tática, mas não a estratégia do ataque à floresta. A remoção da cobertura florestal nas condições desse novo regime de pequenas propriedades, menores que o normal e subcapitalizadas, provavelmente era muito mais rápida e mais completa. (Dean, 1996, p. 256)

Por isso, segundo Claudia Sonda, é comum a maioria dos remanescentes florestais, existentes hoje no Paraná, estarem em grandes propriedades (1996, p. 26.). O pequeno agricultor necessitava de toda a terra para a sua sobrevivência, já o grande e o médio agricultores, às vezes, poderiam deixar áreas florestadas que fossem impróprias ou com baixa possibilidade de aproveitamento agrícola. Em Engenheiro Beltrão, em 1970, conforme o Censo Agropecuário, 28\% dos estabelecimentos agrícolas possuíam até 5 hectares, com uma área média de 3,9 hectares. Eram, portanto, minifúndios dos quais uma família teria dificuldade de tirar sequer sua subsistência, dentro do padrão 
agrícola predominante. Sendo a maioria dos estabelecimentos, 59,62\%, (Tabela 1), de não proprietários (parceiros e arrendatários), os quais sabiam estar em uma situação instável, o que contribui para sobre-explorar "a base de recursos naturais”. Cabe uma digressão sobre como os conflitos sociais têm efeitos sobre a base de recursos naturais. A cultura intercalar e a caça são dois exemplos de conflitos sociais com efeitos sobre a base de recursos naturais.

A cultura intercalar, ou seja, o cultivo nos intervalos dos cafezais, o qual era destinado para o consumo ou comercialização por parte do colono/parceiro, era suportada no cafezal, quando novo. Todavia, conforme o café crescia, a cultura intercalar — como milho e feijão - competia com a cultura principal pelos nutrientes. Verena Stolcke (1986) mostra como entre os colonos em São Paulo isso era um elemento de disputa, pois os colonos estavam, em geral, dispostos a ampliar esse cultivo e os proprietários a suprimi-lo. Em Engenheiro Beltrão, o entrevistado José (n. 12) narra a história de sua irmã e de seu cunhado que, em 1955, trabalhavam como parceiros, e que a colheita de café foi perdida em virtude da geada. Seus parentes queriam voltar para Minas Gerais, mas o proprietário - talvez preocupado com a falta de bons trabalhadores — os convenceu a ficar na terra, pois poderiam podar o café e, nas palavras do entrevistado, o proprietário teria afirmado que: “o senhor pode plantar ... até dentro da cova de café, pode largar feijão, milho”. Isso mostra como a cultura intercalar era um termo de negociação no conflito entre não-proprietários e proprietários.

Um outro exemplo é a caça, fonte preciosa de um alimento apreciado, a carne, porém vista de forma pejorativa por alguns entrevistados: "nunca fui caçador ... agora trabalhar ... isso sim, agora pescador, caçador, jogador, não, nada disso comigo” (Antenor, n. 29), sendo entendida como uma atividade perniciosa, comparável ao jogo de azar e como um não-trabalho. Talvez isso se explique por tal atividade desviar o “colono/parceiro" para outras atividades que não “cuidar da lavoura”. Afinal, no contrato por percentagem o lucro do dono da terra dependia de que o café fosse bem cuidado.

São também exemplos de como a opção por entrevistar um grupo específico, fundamentalmente agricultores proprietários que ainda residiam no município, limita o “campo de visão” sobre outros “usos e abusos” da floresta. Deter-se-á, novamente, nos agricultores, mais especificamente para a atividade de “derrubada”.

O desflorestamento não se efetuou todo de uma vez. A parte mais alta do terreno, em geral, era desflorestada para o plantio do café. Mas, como a residência 
ficava na parte baixa, perto do córrego, era ali que começava a derrubada. Alguns relatos informam que nos primeiros anos havia uma faixa de mato entre a parte alta e a parte baixa do imóvel. Outros cultivos incentivaram o desflorestamento para a agropecuária na fase de (re)ocupação, em especial o hortelã, por não ter as mesmas limitações que o café, podendo ser plantado nas "baixadas” (o café não pode ser plantado nas regiões baixas em virtude das geadas).

Um analista da época assim descreve o processo de derrubada da mata:

O primeiro ato do cultivador não é lavrar a terra, mas desflorestar. Começa-se pela roçada, isto é, a limpeza à foice da subfloresta que se efetua em maio, no princípio da estação da seca; deixa-se durante algumas semanas, de maneira a cobrir o solo com um leito de plantas bem secas, o facho; depois vem a derrubada, que consiste em por abaixo as árvores acima do facho. As mais grossas e as mais duras não são abatidas; ou são deixadas para recobrir com alguma sombra o futuro campo, ou então corta-se a casca na base em forma de anel para impedir a subida da seiva e fazer perecer a árvore dentro de alguns anos; passa-se, enfim, em setembro ou outubro, justamente antes da estação chuvosa, à queimada, ao incêndio (Deffontaines apud Cancian, 1974, p. 72). Para o Norte do Paraná as épocas de derrubada e queimada variam um pouco. A queimada geralmente é feita em agosto (Cancian, 1974, p. 72).

Para Nadir A. Cancian, podem-se distinguir pelo menos três estratégias para a derrubada:

$1^{\mathrm{a}}$ - Os colonos mais pobres abrem uma clareira na mata, constroem uma moradia provisória, geralmente de palmito, e depois procedem à derrubada da mata. Isto é possível no Norte do Paraná onde as terras adquiridas são de poucos alqueires. Em alguns casos são auxiliados pelos vizinhos mais próximos.

$2^{\mathrm{a}}$ - Os colonos com posses maiores contratam o serviço de especialistas em derrubadas. Deffontaines e Monbeing assinalam que tais serviços são prestados geralmente por operários temporários vindos do Norte [sic.] do país, baianos. Sobre serem ou não baianos, é preciso assinalar que eram chamados indistintamente de baianos muitos nordestinos procedentes de outras áreas. (Cancian, 1974, p. 73-4)

Havia uma grande variedade de possibilidades de ação, dependendo principalmente dos recursos disponíveis. Sendo que, no primeiro caso, não necessariamente o agricultor era um proprietário, pois havia a possibilidade de entregar a terra a um parceiro, com "mata em pé e água no córrego". Nesse tipo de contrato, normalmente com duração de seis anos, o café produzido era repartido entre as partes, não necessariamente iguais, já a lavoura intercalar era toda do formador. Como já foi comentado, esses “contratos” podiam variar muito em suas cláusulas.

\footnotetext{
$3^{\mathrm{a}}$ - Há ainda um tipo especial, o mateiro, ou extrator de toros. Esse tipo de trabalhador é um verdadeiro profissional em extração madeireira. Conseguia derrubar uma árvore mesmo entre cafezais, na mata virgem [sic.] ou onde quer que se localizasse. Para se conhecer bem todo o processo, é preciso dizer que ele exerce várias funções. Pode adquirir a madeira em pé, por sua própria conta, derrubá-la e vendê-la depois às serrarias. Nesse caso, age como extrator e intermediário. Compra e vende madeira. Os gastos correm por sua conta. Pode ainda ser contratado por uma serraria que comprou a madeira em pé e precisa derrubá-la. Nesse caso, os
} 
seus serviços são contratados e as despesas podem ou não correr por sua conta, dependendo do contrato ... que ... [s]ão geralmente à base da palavra empenhada. (Cancian, 1974, p. 74-5)

Nas entrevistas realizadas não há registro desta atividade, salvo, talvez, a citação do entrevistado Lucidio (n. 23), que relata que na fazenda em que trabalhou, entre 1949 e 1963, uma de suas funções era proteger a área que foi invadida várias vezes, em especial para a extração da madeira nobre como cedro e peroba. De onde deprendemos que nem sempre ou nem todos os mateiros eram contratados, o simples furto das árvores era possível, especialmente conforme a (re)ocupação ia se completando e a floresta começava a ficar mais escassa, o que aconteceu de forma muito rápida.

Embora no século XIX a terra florestada fosse vendida em geral pela metade do preço da terra desmatada, refletindo o custo da derrubada, agora as terras florestadas custavam mais. Em dezoito municípios pesquisados na Zona da Mata de Minas Gerais em 1905, a floresta primária era avaliada $70 \%$ acima da terra desmatada ... O preço da floresta primária em cada um desses municípios estava associado não à sua escassez absoluta, mas ao valor da terra desmatada, sugerindo que os fatores que determinavam seu preço eram a fertilidade do solo e o clima do município, donde seu potencial para o cultivo de café. O que está implícito na alteração desses percentuais é que, em algum ponto inicial do povoamento, havia vantagem em não levar a floresta ao mercado, mas que essa vantagem desapareceu bem cedo - as faixas finais da floresta primária não aumentariam continuamente de valor, mas acompanhariam o mercado de terra desmatada. Não era, portanto, promissora especulação com essas faixas e também não havia perspectivas de longo prazo para sua sobrevivência. (Dean, 1996, p. 262-3)

Em Engenheiro Beltrão, ainda, no início da década de 1950, era mais caro comprar uma área "limpa” do que uma área com o "mato em pé”. A exploração da madeira, de acordo com Claudia Sonda, foi "bastante seletiva e exclusivamente calcada na prática extrativista”, sobretudo na floresta estacional semidecidual, a floresta foi pouco aproveitada economicamente (Sonda, 1996, p. 25).

Algumas memórias do período lembram estupefatas de tamanho desperdício de recursos naturais no norte do Paraná:

João Tenório Cavalcanti ... dirigia uma turma que chegou a integrar 800 homens, um verdadeiro exército de "machadeiros" que liquidou o maior perobal do mundo, reduzindo grande parte a cinzas, nas queimadas que somavam léguas. Dava pena ver as chacinas dos gigantes troncos, com séculos de existência, deitados inermes sobre a terra, com as entranhas a fervilhar em fogo. (Estrada, 1961, p. 17 apud Paula, 1998, p. 70) (grifo nosso)

Não há trabalho que permita mensurar o tamanho do desperdício de recursos naturais, ou da extinção da biodiversidade, apesar de haver trabalhos que especulem sobre esta questão. Pode-se aqui recordar Dean (1996, p. 23) e pensar que não há como não vermos, hoje, tal processo de desflorestamento como algo trágico, afinal a biodiversidade da floresta é tal, e com tal endemismo, que podemos supor que o 
processo de desflorestamento, apenas da área de Engenheiro Beltrão, foi responsável pela extinção de espécies, as quais nem sequer chegamos a conhecer.

Porém, é certo que, “diferente da situação da fronteira cafeeira dos primeiros tempos, algumas das árvores estavam sendo cortadas para madeira, mais do que meramente queimadas” (Wagley, 1963, p. 91).

\section{INDÚSTRIA MADEIREIRA}

Na primeira metade do século XX, temos uma grande transformação na forma de exploração das florestas no Brasil. Segundo Dean, introduz-se uma sistemática remoção da madeira. No Vale do Ribeira, passou-se a comprar a terra somente para explorar a madeira, ao invés de simplesmente queimá-la. "No fim da década de 20, caminhões a gasolina e serrarias portáteis movidas a máquina de [sic] vapor tornaram econômico um tráfico terrestre de madeiras de lei” (Dean, 1996, p. 265). Ainda de acordo com Dean, muito provavelmente tal exploração da madeira é a causa da inversão dos preços das terras, com a terra florestada superando o preço da terra desmatada. "As vendas de madeira podiam facilmente igualar o custo do desmatamento da terra” (Dean, 1996, p. 265).

O Brasil só passou a exportar mais madeira do que importava durante a Primeira Guerra Mundial (Souza, 1947, p. 14-15). E no estado do Paraná foi só durante a década de 1920 que tal produto passou a ter grande importância econômica para o Estado, o transporte era o principal ponto de estrangulamento na cadeia produtiva e as ferrovias é que permitiram, até certo ponto, a comercialização da madeira. Mas essa produção paranaense era principalmente de "Pinho do Paraná”, a Araucária angustifólia, madeira abundante no centro-sul e a oeste do estado. Nas matas do norte do estado, era escassa, predominando, neste tipo de floresta uma série de outras madeiras nobres (Lalalle, 1974).

\footnotetext{
Alguns analistas da época chegaram a maldizer o que seria chamado hoje de biodiversidade da floresta brasileira, pois as florestas temperadas, constituídas muitas vezes de apenas uma espécie predominante, possibilitavam um maior ganho econômico, o que ocorria, de certa forma, nas matas de pinhais do Paraná e dos outros estados do Sul do país. Nas florestas tropicais, em geral, apenas algumas espécies têm as qualidades exigidas pelo mercado consumidor, e elas estão espalhadas, com apenas alguns indivíduos da espécie no meio de uma densa floresta. Até mesmo a legislação florestal apresentou uma diferenciação entre as florestas "homogêneas" e as "heterogêneas", a qual somente foi superada na década de 1980. Para as florestas homogêneas havia formas de conservação — racionalização do uso — já para as florestas “”mistas”, eram “consagradas” aо “corte raso”. (Bohn, 1990)
} 
Para se ter uma idéia do aproveitamento das florestas "heterogêneas", como a estacional semidecidual, na Serraria São Carlos, em Cambé, no norte do Paraná, estudada por Nadir A. Cancian, foram encontradas apenas as "espécies: peroba, cedro, pinho, canelão, cabreúva, caviúna, marfim, coração de negro, amoreira, imbuia” (Cancian, 1974, p. 67). Desta forma,

essas madeiras espalhadas pela floresta primária latifoliada eram difíceis de transportar. Uma pequena parte teve uso local, principalmente para a construção das casas de madeira e galpões típicos dessa fase “pioneira”, mas a maioria era queimada in loco. (Nesella \& Alcântara, 2002, p. 11)

Alexandre Beltrão, engenheiro responsável pela Sociedade Técnica Colonizadora Engenheiro Beltrão, destacava no Plano de Colonização da Gleba Mourão que:

As terras são, em sua quase totalidade revestidas de mata virgem, [sic.] com o predomínio da vegetação característica de todo o vale do rio Ivaí, na qual as árvores de maior porte e as mais comuns são perobas, cedros, figueiras, paus d’alho, alecrins, monjoleiros, sobrasil, caviúnas, cajaranas, angicos, etc. (Beltrão, 1947, p. 27)

E destacava que: "na faixa de terras marginais ao ribeirão da Cachoeira e ao córrego de Saltinho, encontram-se pinheiros, em terrenos próprios para a criação de gado” (Beltrão, 1947, p. 27).

A oeste do atual município de Engenheiro Beltrão, “para os lados de Campo Mourão”, havia uma extensa área de floresta de araucária, as quais eram mais cobiçadas pelos madeireiros. Na Gleba Mourão sua incidência se dava apenas em algumas faixas. A comercialização da madeira era limitada, o desflorestamento é lembrado como um custo. Quando se perguntou ao agricultor Antônio por que desmatou o seu sítio aos poucos, afirma que: era "porque o recurso era pouco, então você ia derrubando a maneira do possível” (n. 24), o que nos leva a pensar que a venda da madeira de um lote rural, em geral, não pagava a derrubada e a preparação do terreno para o cultivo, pelo menos nos primeiros anos da colonização dirigida.

Para Nadir A. Cancian, foi o avanço da fronteira agrícola o principal motivador da ação das madeireiras:

A exploração madeireira só foi significativa enquanto se completava esta ocupação, o que, aliás, se fez de forma muito rápida. ... Pode dizer-se que a serraria é pioneira na abertura de regiões, aproveitando-se das madeiras liberadas pela ocupação agrícola das terras. Nota-se o movimento de deslocamento das serrarias à medida que a colonização ou as novas frentes pioneiras penetram mais para o interior. (Cancian, 1974, p. 5) 
Tanto que foi exatamente no período da (re)ocupação em que ocorreu a expansão da indústria madeireira: no “Norte do Paraná ..., por volta de 1935, as serrarias eram em número de 11, e catorze anos depois, em 1949, perfaziam um total de 177 serrarias registradas no I.N.P.” (Instituto Nacional do Pinho) (Cancian, 1974, p. 204). As serrarias e a extração madeireira foram atividades transitórias na região:

\begin{abstract}
a tal ponto que se pode dizer que, quando as serrarias operam com peroba, pinho, cedro, cabreúva, marfim e outras madeiras preciosas, estão na plenitude dos lucros financeiros, com uma duração média de 25 anos em uma região, ao passo que quando começam a serrar paud’alho, madeira de pouco valor comercial, já é a decadência pelo esgotamento da matéria-prima de fácil acesso, pois madeiras inferiores não compensam comercialmente a produção, quer pela qualidade, quer pelo preço. Isto não quer dizer que, além desse limite de tempo, não possa haver serraria funcional em uma área determinada. Mas, ou são firmas de grandes recursos financeiros que podem operar trazendo a matéria-prima de longa distância, ou se transformam em verdadeiras fábricas de artefatos de madeira, o que lhes permite um aproveitamento maior da matéria-prima, transformando-a em diversos produtos secundários cujos preços compensam os fretes pagos no transporte de longo curso. (Cancian, 1974, p. 71-2)
\end{abstract}

Engenheiro Beltrão segue a trajetória tradicional da indústria madeireira no Brasil. A primeira serraria (Engenheiro Beltrão, 1985, p. 5) instalada logo depois do início da atuação da Sociedade Técnica Colonizadora Engenheiro Beltrão pertencia a Aldevino Santiago. Já em 1960, nos anos de auge da produção de madeira (Tabela 2), ${ }^{3}$ o Censo Industrial informa sete empresas madeireiras no município. Na década de 1970, conforme a madeira ia escasseando, passou-se a serrar uma variedade maior de espécies arbóreas, mas estas tinham baixo retorno econômico, as serrarias que não mudaram para regiões de fronteira agrícola começaram a trazer toras de cada vez mais longe e diversificar as atividades, mas hoje resta apenas uma minisserraria na cidade.

\begin{tabular}{crr}
\hline \multicolumn{3}{c}{ TABELA 2 - ENGENHEIRO BELTRÃO - PR.: MADEIRAS } \\
\hline ANO & M3 \\
\hline 1956 & & 5.800 \\
1957 & & 7.300 \\
1958 & 278.986 \\
1959 & 7.538 \\
1960 & & 62.000 \\
1961 & & 62.000 \\
1962 & 15.900 \\
1963 & & 12.000 \\
1964 & 8.000 \\
\multicolumn{2}{c}{ Fonte: Departamento Estadual de Estatística - Paraná. apud: CANCIAN, Nadir Apparecida. } \\
Conjuntura econômica da madeira no norte do Paraná. 1974. Dissertação (Mestrado em História) \\
- Universidade Federal do Paraná. Curitiba. 2 v. p. 453-461. \\
\hline
\end{tabular}


A simples queima da floresta, sem a retirada das espécies nobres, era predominante, no período anterior à atuação da colonizadora, e nos primeiros anos de sua atuação, motivada sobretudo pela dificuldade no transporte, que era rodoviário. Essa dificuldade de transporte foi resolvida gradualmente, a ausência de estradas ou as péssimas existentes permaneceram um problema tanto para escoamento dentro do município como para a principal via de acesso ao mercado mais amplo, a cidade de Maringá - distante 65 quilômetros, a estrada foi aberta no final da década de 1940, mas o problema só foi efetivamente resolvido com o asfaltamento da rodovia, já no final dos anos 1960, quando o "ciclo" madeireiro se esgota. Seguindo a trajetória típica das indústrias madeireiras no norte do Paraná, os anos de 1958 a 1961 foram o auge da produção madeireira, na média o município produziu 32,3\% da madeira da microrregião de Campo Mourão, já em 1964, apensar da produção de a microrregião ainda estar em ascendência, a produção do município representava apenas $1,7 \%$ da produção total, o que indica que a abertura de outras localidades para agricultura na microrregião liberava a madeira para as serrarias (Cancian, 1974, p. 88, 455-8, 461). No início dos anos 1960, talvez 1/3 das matas nativas ainda restavam no município (ver Tabela 1). O último ano a apresentar uma produção comercialmente significativa de madeira foi 1977, em que oficialmente houve a extração de $36.000 \mathrm{~m}^{3}$.

Mesmo com todas essas dificuldades, havia uma superprodução de madeira, por parte das serrarias, a qual foi responsável, em parte, pelos baixos preços pagos nos grandes mercados consumidores (Cancian, 1974, p. 206). Afinal, não havia falta de fornecedores do produto, ao contrário, os agricultores também mantinham uma superprodução de madeiras para as serrarias, que "não vencia cortar” (Dalpont \& Dalpont, 2003), o que provavelmente mantinha os preços baixos e incentivava o corte hiperseletivo: "Retirava a madeira, mas só tirava a boa, né, naquele tempo só precisava de madeira melhor, tinha madeira sobrando, a ruim a gente largava lá, queimava, apodrecia” (Dalpont \& Dalpont, 2003). Nos anos 1970 e 1980, principal período em que as terras da região foram "mecanizadas”, ou seja, tiravam-se os obstáculos para a circulação de máquinas automotoras agrícolas, muitos troncos de árvores tinham que ser retirados do meio das "roças", em alguns casos, troncos com 20 ou 30 anos de derrubada foram serrados para aproveitar o que havia se tornado uma mercadoria nobre. 


\section{A PERCEPÇÃO COMO FATOR PARA DESFLORESTAR}

Há outros fatores que se deve levar em conta para entender o processo de devastação da floresta, um deles se expressa ao chamarem a floresta de "mato", considerando que “mato” não é apenas a floresta primária, é também a capoeira, e mais, qualquer planta que nasça em lugar indesejado ("praga”), as quais o agricultor tem por ofício carpir, eliminar, para limpar o terreno. Um dos entrevistados afirmou, que se ele "zelasse" (Francisco, n. 10) — retirasse o "mato" - da barranca do rio, ela desbarrancaria. Assim, qualquer área de “mato” (não “zelada”) foi entendida como uma área inculta, na qual não se trabalha.

Todo o período anterior à modernização é lembrado por aqueles que o viveram, com uma ênfase muito grande no trabalho: “a gente só trabalhava, não saía pra ..., nem rádio quase a gente não ouvia, né, televisão não tinha também, então a gente às vezes chegava domingo sem saber que dia era da semana” (Leonardo n. 20) (grifo nosso).

O essencial a ser retido é a presença do discurso do trabalho. O trabalho como um valor fundamental, que estava e está presente na fala dos agricultores.

Podemos inferir que manter “mato” na propriedade é manter a “terra inculta”, é não trabalhar, portanto, um ato moralmente condenável para esse grupo social. Assim, torna-se necessário considerar tal "discurso do trabalho" para entendermos a derrubada tão completa das matas na área estudada. ${ }^{4}$

Segundo Eric Hobsbawm, "para os camponeses, a posse sem trabalho é impensável, uma vez que toda a terra que tenham deve ser utilizada”. Para além do discurso moderno do trabalho, isto seria parte dos "pressupostos sociais, políticos e do pensamento estratégico subjacente” (Hobsbawm, 1998, p. 241-4) aos camponeses ocidentais. Uma outra fonte para a legitimidade moral da idéia de que terra "em que não se trabalha” pode ser ocupada, e terra em que se trabalha, se tem direito a posse, é sugerida por José de Souza Martins, ao afirmar que:

Uma característica importante da frente de expansão em todo o país, para datá-la historicamente, é que quando se deslocavam juntos ricos e pobres deslocavam-se com base nos direitos assegurados pelo regime sesmarial. Embora o regime de sesmarias tenha cessado às vésperas da Independência e só tenha sido substituído por um novo regime fundiário com a Lei de Terras de 1850, ele continuou norteando as concepções de direito à terra de ricos e pobres e, em muitos casos, norteia até agora. A concepção de que é preciso ocupar a terra com trabalho (na derrubada da mata e no seu cultivo) antes de obter reconhecimento de direito, era próprio do regime sesmarial. Do mesmo modo, a concepção de que o trabalho gera direito de propriedade sobre os frutos do trabalho também era próprio desse regime fundiário. Nele, o domínio estava separado da posse. O domínio era da Coroa. Quando, por acaso, o sesmeiro deixasse de cultivar a terra ou de obter dela frutos para pagar tributos, a terra se tornava devoluta (ou realenga, como então se dizia, isto é pertencente ao rei). Podia por isso ser novamente distribuída pelo representante da 
Coroa, bastando que alguém a ocupasse e, depois, a requeresse, como ocorreu freqüentemente. Do mesmo modo, a casa de um agregado construída em terras de sesmaria ou data de outrem, bem como suas roças e cultivos, não sendo ele escravo, lhe pertenciam legalmente, sendo a relação com o sesmeiro apenas relação de enfiteuse. Portanto, o trabalho de fato gerava direito sobre bens produzidos e sobre a terra beneficiada ou, melhor, sobre o benefício incorporado à terra, como era o caso do desmatamento. (Martins, 1996, p. 43-4)

Martins, ao argumentar sobre essas persistências do "imaginário monárquico”, na frente de expansão, afirma que isso não se deve apenas a “arcaísmos religiosos”, “mas também a uma concepção de direito muito próximo dos pobres: a dos direitos (de uso) gerados pelo trabalho em oposição aos direitos (de propriedade) gerados pelo dinheiro” (Martins, 1996, p. 44). Não cabe, entretanto, aqui debater sobre a gênese desta idéia, e sim o que interessa para esta pesquisa, que é constatar a sua persistência.

Não se quer aqui afirmar que os agricultores estudados vivem dentro de uma ordem moral tradicional (Woortmann, 1987), mas apenas apontar a persistência de alguns valores que continuam presentes em novas configurações. Ainda hoje, mesmo entre os agricultores "bem de vida”, que, em geral, repudiam a ocupação de terras promovida pelo Movimento dos Trabalhadores Rurais Sem Terra (MST) para pressionar a execução da reforma agrária, o argumento de que os "trabalhadores” têm o direito de “ocupar” a terra “inculta” é considerado válido.

Tal princípio moral tem implicações para a floresta na época da (re)ocupação da região, terra com “mato” poderia ser “ocupada” com uma certa legitimidade, não legal, mas moral. Houve uma imagem produzida pelas empresas colonizadoras e pela elite agrária da região que no norte do Paraná não ocorreram conflitos pela terra (Gonçalves, 1994). Todavia, são inúmeros e intensos os conflitos pela posse da terra na história da (re)ocupação do "sertão" do Paraná. Ter alguém morando e/ou poder político/econômico/“de fogo” para manter "invasores” fora da propriedade era a forma de garantir uma posse "pacífica”. Uma área com "mato” sem vigilância poderia ser “ocupada” ou explorada por terceiros, como indica o relato do entrevistado Lucidio n. 23, já citado, sobre a sua ação para conter invasores que queriam extrair madeiras nobres, como cedro e peroba, da fazenda em que trabalhou até 1963. Manter a área "limpa”, sem mato, era uma forma que ajudava a confirmar a posse ou a propriedade, em especial em uma frente pioneira, há pouco “aberta”, cheia de conflitos pela posse da terra e onde "velhos valores e concepções” poderiam aflorar para legitimar posições.

E não apenas o juízo moral dos agricultores possuía elementos “contra” a “floresta/sertão”, mas, também, seu juízo estético os possuía. Havia e há um apreço pela 
“natureza desnaturalizada”, ordenada e racionalizada, entre os agricultores estudados, (Pereira, 1999, p. 11-47), ou seja, “bonito” é a “carreira” de eucaliptos, homogêneos e não a “floresta/sertão”, “caótica”. Como bem expressa o comentário do Sr. “Leonardo”:

Onde é pedreira que não dá para mecanizar, e fazer de enxada dá prejuízo, então nós plantamos uma moita de eucalipto ... 50 metros assim ... então desmatamos aquilo lá, cortamos aquele colonhão, carpimos, e plantamos eucalipto, dá uma moita bonita, né. (Leonardo, n. 20)

Há uma grande valorização em manter-se "limpa” a terra. E, isso não visa necessariamente a um aumento de produção, algo utilitarista. Santo Bergo, avô de Ely Bergo de Carvalho, por exemplo, possuía uma “mata” que ficava em torno de uma nascente no seu sítio em Engenheiro Beltrão. Não se cultivava nada, mas ele fazia absoluta questão de manter a área, sob as árvores, "limpa”, e gastava muitas horas de serviço em tal atividade. Manter um terreno "limpo" era reafirmar que naquela área se trabalhava, reforçando-se a auto-imagem de trabalhador, reforçava-se, ainda, a propriedade/posse da terra. Mas é, também, um exemplo de como o grupo pesquisado tem dificuldade de considerar "belo e aprazível” o "mato”, bonito mesmo é terra "bem cuidada”. As árvores isoladas, o pomar, a silvicultura, o campo cultivado são bonitos, já “mato” é, por definição, o antônimo disso, é “terra inculta”, é “sertão”.

\section{A “FLORESTA/SERTÃO”}

De “inferno verde” a "paraíso tropical”, nosso imaginário sobre as florestas é repleto de diversidade (Schama, 1996, p. 541). E mais, a floresta é um lugar de diversidade, não só biológica, a floresta na fronteira - na frente de expansão e na pioneira - é um lugar de encontro com o Outro, em alguns casos é o lugar do Outro, é também onde os ocidentais/modernos se amedrontam por estar longe da civilização, mas também ficam felizes por estar livres da civilização.

Disso resulta a dificuldade de se tentar apreender a diversidade, como se fosse algo coeso. Marcos Gerhadt (2002), estudando a “Colonia Ijuhy”, situada no interior do Rio Grande do Sul, entre meados do XIX e princípio do XX, afirma que há uma ambivalência diante das florestas, é um lugar associado a perigo, desconforto e também é um local que é fonte de recursos necessário, um lugar de abundância.

No caso em estudo, para alguns agricultores, a floresta era um lugar que dava medo: "tinha dia que dava medo, né, no meio daquele matão, assim um bicho pegava, 
né, sei lá...” (Leonardo, n. 20), para outros, a presença da floresta era mais bem-vinda, pois “era bom, que a gente caçava, a gente pescava” (Lucidio, n. 23).

Apesar de a floresta suscitar uma diversidade de lembranças há uma associação que é recorrente na fala dos agricultores, a saber, a de que a floresta, ou melhor, o “mato” é sinônimo de “sertão”. O entrevistado Luiz afirma que “na fronteira tem sertão ... tem mato até hoje” (n. 1), e o entrevistado Bento, quando perguntado se as terras que sua família comprou em Ibiporã-PR, eram “limpas”, ele responde: “Não, lá era sertão era tudo mato” (n. 11). Pode-se afirmar, portanto, que a floresta é lembrada pelos agricultores como uma “floresta/sertão".

A “floresta/sertão” é lembrada, principalmente, como um lugar inóspito. O “sertão” era um lugar perigoso, no qual não se tinha os confortos dos lugares “desenvolvidos” e no qual se pensava muito para se colocar a família: O entrevistado Luiz afirma que na década de 1950 a região de Engenheiro Beltrão era: “chamada de virador, ... a pessoa vinha aqui, naquela época aqui era sertão, aqui era mato, chegava aqui, virava para trás e ia embora, e pronto. Voltava para casa. ... (rindo)chegava aqui, não se agradavam, negociavam e voltavam para trás” (n. 1).

A floresta é lembrada, ainda, como “nada”. Quando perguntado a um agricultor como era a região quando ele chegou, ele afirma: "não tinha nada ..., só mato" (Herman, n. 25). Um outro agricultor a respeito das terras para qual se mudou, na fronteira agrícola paraguaia, afirma que: era "tudo mato, não tinha nada” (Alcides, n. 26). A floresta é “mato” e "mato” é um “nada”. A floresta era o antônimo de "tudo” o que era conhecido para eles, era a não-estrada, a não-casa, a não-lavoura.

A floresta era um obstáculo a ser superado, um "nada”, um marco zero a partir do qual se constrói a história da realização do sonho geral de se tornar ou manter-se proprietário rural - ou simplesmente de “ficar rico". Isso diante do problema de uma família que estava aumentando, muitas vezes em áreas de origem que estavam por demais degradas para manter o padrão de vida. Em uma sociedade na qual a “concentração fundiária” é um traço secular em sua história, que permitia a especulação da terra para os "grandes” e forçava os "pequenos" a sobreexplorarem sua "base de recursos naturais”, dentro de um "modelo de agricultura”, que mais se parecia com uma “onda”, não tão “verde”, de degradação ambiental (Maack, 1963, p. 32; Woortmann, 1995).

Foi a partir de tais formas de apropriação e representação da floresta que os agricultores contribuíram para transformar o que era um “sertão” em civilização, como 
ressalta o entrevistado José: “quando eu cheguei aqui, era sertão, [1957] ..., uma mata velha desgraçada” (n. 12). A compreensão dessas formas de apropriação e representação contribui para iluminar o radical processo de desflorestamento gerado no avanço da fronteira agrícola, no século XX, no Brasil.

\section{REFERÊNCIAS BIBLIOGRÁFICAS:}

ARRUDA, G. Cidades e Sertões: Entre a história e a memória. Bauru: Edusc, 2000.

BELTRÃO, A. Plano de loteamento: Memorial referente ao Terreno denominado Rio Mourão. Curitiba, set. 1947. (Arquivo Público do Paraná).

BOHN, N. A legislação ambiental e sua implementação frente a degradação da cobertura florestal no vale do Itajaí. 1990. Dissertação (Mestrado em Ciências Humanas - Especialidade Direito) - Universidade Federal de Santa Catarina, Florianópolis.

BRANNSTROM, C. Repensando a Mata Atlântica brasileira: cobertura vegetal e valor da terra no Oeste Paulista, 1900 a 1930. Varia História, Belo Horizonte, n. 26, p. 58-76, jan. 2002.

CANCIAN, N. A. Cafeicultura paranaense 1900-1970 - estudo de conjuntura. 1977. Tese (doutorado em história) - USP, São Paulo, 1977. . Conjuntura econômica da madeira no norte do Paraná. 1974. Dissertação (Mestrado em História) - Universidade Federal do Paraná. Curitiba. 2 v. 1974.

DALMORA, E. Contradições na conservação e entendimento da mata entre técnicos e agricultores familiares de Lindóia do Sul e Ibirama, SC. In: Simpósio de Etnobiologia e Etnoecologia da Região Sul, 1, 2003, Florianópolis. Anais. Florianópolis: UFSC, 2003.

DALPONT, J.; DALPONT, F. B. João Dalpont; Fortunata B. Dalpont: depoimento [24 abr. 2003]. Engenheiro Beltrão, 2003.

DEAN, W. A ferro e fogo: A história e a devastação da Mata Atlântica brasileira. São Paulo: Companhia das Letras, 1996.

DEFFONTAINES, Pierre. A floresta a serviço do homem no Brasil. Boletim Geográfico. Rio de Janeiro, v. 28, n. 3, p. 564, 1945 apud CANCIAN, N. A. Conjuntura econômica da madeira no norte do Paraná. 1974. Dissertação (Mestrado em História) Universidade Federal do Paraná. Curitiba. 2 v.

ENGENHEIRO BELTRÃO. História, Pioneiros, Atualidades: Engenheiro Beltrão. Engenheiro Beltrão, 1985. 
- Projeto do Município de Engenheiro Beltrão: Programa de Florestas

Municipais, 1996.

ESCRITURA de constituição de sociedade civil por quotas de responsabilidade limitada denominada "Sociedade Técnica e Colonizadora Engenheiro Beltrão Limitada... 1947. Arquivo do Cartório de Registro de Títulos e Documentos $1^{\circ}$ Ofício, Curitiba.

ESTRADA, Duque J. F. Terra Crua. Curitiba: [s.n.], 1961 apud PAULA, Z. C. de. Maringá: o coração verde do Brasil? 1998. 270 p. Dissertação (Mestrado em História) - Universidade Estadual Paulista - UNESP, Assis.

GERHARDT, M. Estado, estancieiros, caboclos e colonos modificam o ambiente: a história da “Colonia Ijuhy” 1850-1930. 2002. Dissertação (Mestre em História). UEM/UEL, Londrina.

GONÇALVES, J. H. R. O espaço regional como ideologia: anotações sobre algumas coreografias políticas do norte do Paraná. Cadernos de METEP, Suplemento História, Maringá, v. 6, n. 5, supl. 1, p. 1-40, 1994;

HOBSBAWM, E. Ocupações de terra por camponeses. In: Pessoas extraordinárias: resistência, rebelião e jazz. São Paulo: Paz e Terra, 1998. p. 241-276.

LALALLE, C. M. A madeira na economia paranaense. 1974. Dissertação (Mestrado em História) - UFPR, Curitiba.

MAACK, R. O ritmo da devastação das matas no Estado do Paraná. Ciência e Cultura, v. 15, n.1, p. 25-34, mar. 1963.

MARTINS, J. de S. O tempo da fronteira: retorno à controvérsia sobre o tempo histórico da frente de expansão e da frente pioneira. Tempo Social, São Paulo, v. 8, n. 1, p. 25-70, maio, 1996.

NESELLA, M. L. B.; ALCÂNTARA, J. C. O desmatamento no norte do Paraná: um recorte comparativo ambiental. Teia, Maringá. Disponível em: <www.pea.uem.br;teia;teia-art_04.html>. Acesso em: 08 jan. 2002.

PAULA, Z. C. de. Maringá: o coração verde do Brasil? 1998. 270 p. Dissertação (Mestrado em História) - Universidade Estadual Paulista - Unesp, Assis.

PEREIRA, M. R. de M. De árvores e cidades ou a difícil aceitação do verde nas cidades de tradição portuguesa. In: SOLLER, M. A.; MATOS, M. I. S. (Orgs.). A cidade em debate. São Paulo: Olho d’Água, 1999.

SCHAMA, S. Paisagem e Memória. São Paulo: Cia. das Letras, 1996. 
SONDA, C. A cobertura florestal nas explorações agrícolas: quem tem e quem não tem floresta. Análise Conjuntural, v. 18, n. 11-12, p. 25-27, nov./dez. 1996.

SOUZA, P. F. de. Indústria Madeireira. Rio de Janeiro: Imprensa Nacional, 1947.

STOLCKE, V. Cafeicultura: Homens, mulheres e capital (1850-1980). São Paulo: Brasiliense, 1986.

TOMAZI, N. D. Norte do Paraná: História e Fantasmagorias. 1997. Tese (Doutorado em História) - Universidade Federal do Paraná, UFPR. Curitiba.

WAGLEY, C. An introduction to Brazil. New York: Columbia University Press, 1963.

WOORTMANN, E. F. Herdeiros, parentes e compadres: colonos do sul e sitiantes do nordeste. São Paulo: Hucitec, 1995.

WOORTMANN, K. “Com parente não se negoceia”: O campesinato como ordem moral. Anuário Antropológico, p. 11-73, 1987.

CARVALHO, Ely Bergo de e NODARI, Eunice Sueli. The perception in the landscape transformation: The farmers in the deforestation of Engenheiro Beltrão - Paraná, 1948-1970. História, São Paulo, v. 26, n. 2, p. 269-287, 2007.

Abstract: The agricultural boundary expansion is the main deforestation cause in Brazil and studying the farmers' perception is fundamental to understand such process. This environmental history research is limited to Engenheiro Beltrão City, located in Paraná, from 1984, which was the beginning of the guided colonization, to 1970. It was used the oral history methodology, by the elaboration of 37 interviews. The main objective is to understand how the farmers have appropriated the forest and represented themselves to it.

Keywords: deforestation, representation, appropriation, farmers.

Artigo recebido em 09/2007. Aprovado em 11/2007.

\section{NOTAS:}

\footnotetext{
* Doutorando do Programa de Pós-Graduação em História da Universidade Federal de Santa Catarina. UFSC. Cep 88.040-100, Florianópolis - Santa Catarina, Brasil. E-mail: elycarvalho@zipmail.com.br. (Bolsista CNPq)

** Professora Doutora do Departamento de História da UFSC. E-mail: eunicenodari@yahoo.com.br.

${ }^{1}$ Foi utilizado como fonte um conjunto de 30 entrevistas realizadas entre maio e setembro de 1998 e 7 entrevistas realizadas no primeiro semestre de 2003 com agricultores beltrandenses. As primeiras entrevistas serão identificadas, nas citações, apenas por um número, de 01 a 30. Na época das entrevistas, optou-se por não identificar nominalmente os entrevistados, pois isso permitiria maior liberdade por parte deles. Já as outras entrevistas serão identificadas com o nome completo do entrevistado.
} 
${ }^{2}$ Há um discurso que caracteriza o processo de (re)ocupação do norte do Paraná como uma "reforma agrária em moldes liberais”. Para uma crítica da produção de tal imagem, ver: Gonçalves, 1994.

${ }^{3}$ Deve ser ressalvado que os números oficiais são pouco confiáveis, pois as serrarias vendiam produtos burlando os controles fiscais, isso quando eram legalizadas, pois muitas serrarias eram ilegais, não registradas em nenhum órgão oficial de controle.

${ }^{4}$ Segundo Eliane Dalmora, os agricultores familiares, descendentes de imigrantes italianos e alemães, de Lindóia do Sul e Ibirama em Santa Catarina construíram um entendimento de mata, que pode ser, "consubstanciada em: mata suja (espaço de não trabalho) x cultura limpa (espaço transformado pelo trabalho humano) e produtivo (reflorestamento) x não produtivo (manejo florestal)” (Dalmora, 2003, p. 188). 